\title{
Liver Transplantation From Donor With Situs Inversus Totalis: Is It a Safety Procedure?
}

Gustavo Rêgo Coelho*, José Francisco Rêgo e Silva Filho, Amaury de Castro e Silva Filho, Luís Eduardo Veras Pinto, Cayo Cesar Goes Texeira and José Huygens Parente Garcia

Department of Surgery, Liver Transplantation Unit, Federal University of Ceará, Ceará, Brazil

*Corresponding author: Gustavo Rêgo Coelho, Department of Surgery, Liver Transplantation Unit, Federal University of Ceará, Capitão Francisco Pedro Street, Fortaleza, Ceará, Brazil, E-mail: gustavorcoelho@hotmail.com

Received date: May 02, 2016; Accepted date: May 26, 2016; Published date: June 03, 2016

Copyright: $\odot 2016$ Coelho GR, et al. This is an open-access article distributed under the terms of the Creative Commons Attribution License, which permits unrestricted use, distribution and reproduction in any medium, provided the original author and source are credited.

\section{Abstract}

Background: The situs inversus is a rare condition of unknown cause that occurs in less than $0.1 \%$ of the population. A standard operation procedure has not been established for liver transplantation when the graft comes from a donor with situs inversus. Counting with this, there are nine cases of transplant with liver graft from deceased donors with situs inversus totalis reported in literature.

Methods - Case Report: During organs harvesting of a young male, it was found that all organs of the abdominal and thoracic cavities were located in changed positions, as if it were a mirror image, diagnosing the donor with situs inversus totalis. The liver was flushed with standard preservation solution and procured using standard techniques.

The recipient was a female with cirrhosis caused by Wilson's disease. She was Child-Pugh C and MELD SCORE 32. Hepatectomy was performed using a piggyback technique with preservation of the vena cava after complete liver mobilization.

The liver graft was brought onto the field and rotated $180^{\circ}$ in a ventral caudal fashion (backwards), maintaining the largest lobe in the right upper quadrant. Twenty-eight months after transplant, the graft liver function was still normal and there were no biliary complications or rejection reactions.

Conclusion: Liver transplantation using a graft from donor with a situs inversus totalis seems to be a safe surgical procedure.

Keywords: Liver transplantation; Situs inversus; Bile duct

\section{Introduction}

The situs inversus totalis is a rare condition of unknown cause that occurs in less than $0.1 \%$ of the population. Several congenital malformations and syndromes like polysplenia syndrome and Kartagener's syndrome are associated with it [1]. There are numerous reports of patients with situs inversus undergoing liver transplantation, however the use of liver graft from a deceased donor with situs inversus is an rare event with only eight cases reported in literature [2-9].

\section{Case Report}

A 32-year-old male had a severe traffic accident and was diagnosed with brain death 3 days after the admission. The potential donor has filled criteria for multiple organ donation and the family accepted the donation. During organs harvesting, it was found that liver, kidneys, pancreas, stomach and all others organs of the abdominal and thoracic cavities were located in changed positions as if it were a mirror image, diagnosing the donor with situs inversus totalis. The liver and the kidneys were flushed with standard preservation solution and procured using standard techniques. During routine backbench preparation of the liver graft, we identify the anatomical relations: common bile duct in the left side, liver artery locating in right, and portal vein behind it. There were no technical difficulties during procurement in the donor surgery.

The recipient was a 34-year-old female patient with the diagnosis of end-stage liver disease caused by Wilson's disease. She was classified as a Child-Pugh C and MELD SCORE 32. The liver transplantation was performed in January 2014. The incision was a bilateral subcostal incision. Hepatectomy of recipient was performed using a piggyback technique with preservation of the vena cava after complete liver mobilization. The hepatic hilum was dissected and we divided the left and right triangular ligaments. The hepatic artery, bile duct, and portal vein were ligated and divided.

The liver graft was brought onto the field and rotated $180 \mathrm{o}$ in a ventral caudal (backward) such that the larger lobe placed in the right upper quadrant as proposed by Pomposelli et al. (Figure 1). The suprahepatic vena cava of the graft was anastomosed with the confluence of the middle and right hepatic vein of recipient with a running 4-0 Prolene suture. The portal vein was then anastomosed end to end with a running 6-0 Prolene suture and the graft perfused. Cold ischemia time and warm ischemia time were 330 minutes and 35 minutes respectively. 


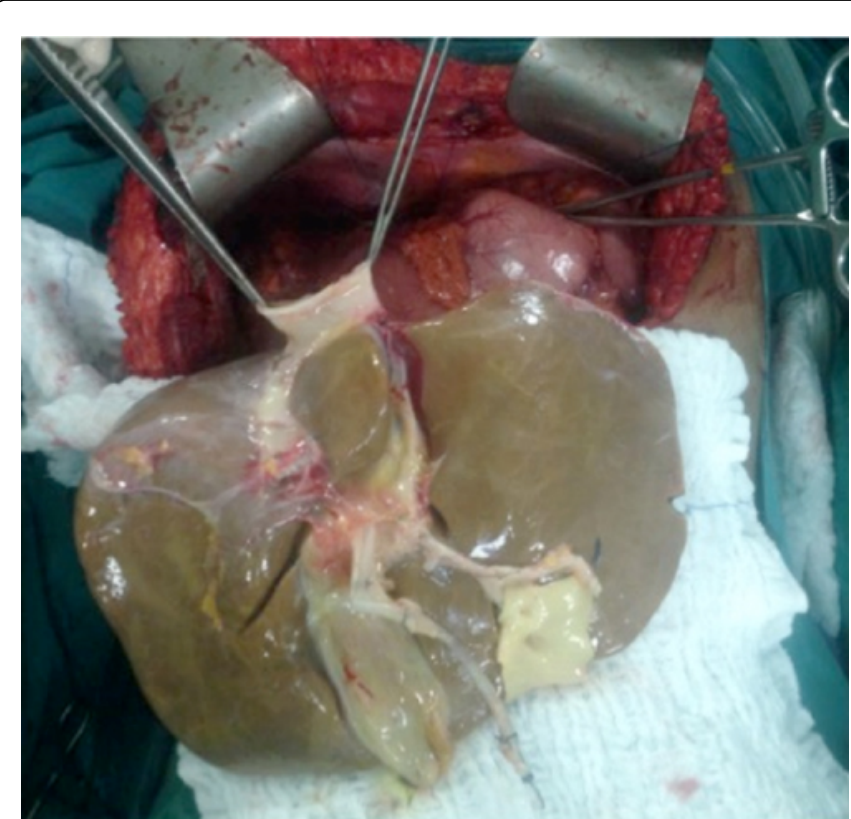

Figure 1: Graft in backward position.

For artery reconstruction we anastomosed the junction of the proper hepatic artery with gastro duodenal artery of the recipient with the junction of common hepatic artery and splenic artery of the liver graft with an interrupted 7-0 Prolene vascular suture. Biliary reconstruction was performed with end-to-end choledochocholedochostomy anastomosis without placing a T-type drainage tube with a running 5-0 PDS suture (Figure 2).

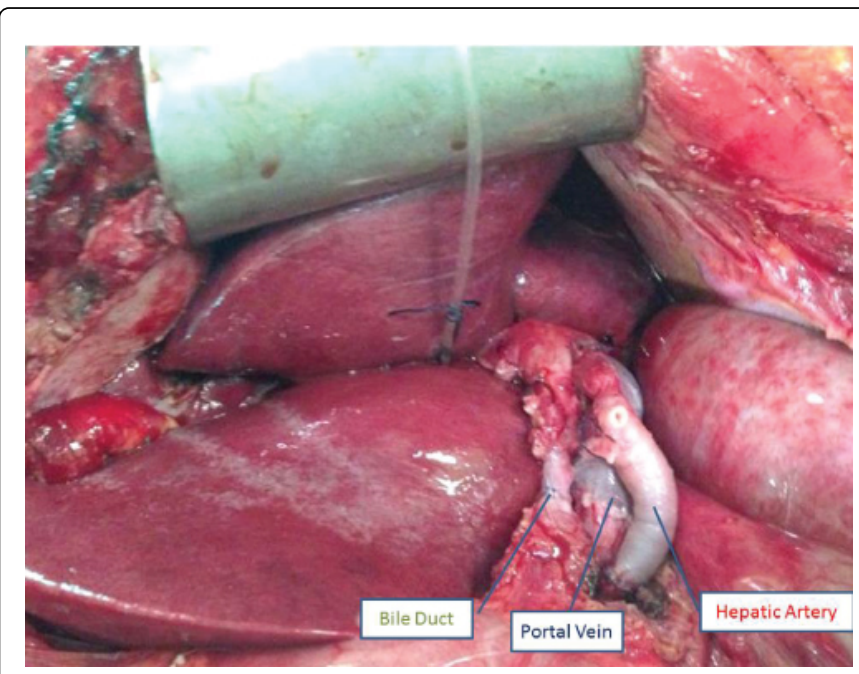

Figure 2: Graft - final appearance.

Post-transplant immunosuppression consisted of tacrolimus, mycophenolatemofetil, and low dose steroids. The patient evolved with good hepatic function but developed infectious and neurological complications in post transplantation. Twenty-eight months after transplant the liver function remains normal without biliary complication or rejection reactions.

\section{Discussion}

The situs inversus is a genetic condition characterized for by a "mirror-image" of all organs from their normal position, and it can be totalis if this variation includes thoracic and abdominal organs [9]. The cause is still unknown and theories range from an acquired cause resulting from an in utero insult and congenital/genetic cause [1].

Until 1988, the presence of this condition in the recipient or in the donor was considered an absolute contraindication for liver transplantation, so experience with liver transplantation in recipients with situs inversus and especially the use of liver grafts from donors with situs inversus is still very limited [5]. The lack of organs for donations is a common problem almost everywhere. In order to enhance usable organ sources, the transplant community is increasingly using organs from marginal donors [7]. The objective of this paper is to try to show that the utilization of marginal donors for liver transplantation, as patients with situs inversus is viable.

A standard operation procedure has not been established in these situations [7]. The first case of liver transplantation using a graft from a donor with situs inversus was reported in 1995 by Asfar et al [3]. During the operation, the liver was counter-clockwise rotated at $90^{\circ}$ and end-to-side anastomose was made between the graft infrahepatic vena cava and recipient's inferior vena cava and end-to-end anastomoses between portal and hepatic arteries were made. For biliary reconstruction, a Roux-en-Y biliary anastomosis has been performed [3]. Herrera et al. and Pomposelli et al. described cases of liver transplantation using a modified piggyback technique with and without rotation of the liver graft [2-4].

Counting with this, there are nine reported cases of liver transplantation with graft from deceased donors with situs inversus totalis in literature [2-9] including a case where the donor and the recipient had situs inversus [8]. Of these cases, including ours, seven transplant patients evolved well being alive when text case was published [3-9]. One patient died on postoperative day 203 and one we had no follow up records [2].

In our case, we have made it similar to Pomposelli's one [2]. After it was put on the field, the liver graft was rotated $180^{\circ}$ in a ventral caudal fashion (backwards) maintaining the largest lobe in the right upper quadrant [2]. In this case, we have made a piggyback technique with orthotopic placement of the liver an end-to-side anastomosis of the vena cava and an end-to-end choledochocholedochostomy without placement of T-type drainage tube. No technical complication of transplant was observed.

In conclusion, liver transplantation from donor with a situs inversus totalis seems to be a safe surgical procedure.

\section{References}

1. Farmer DG, Busuttil RW. Transplantation: Situsinversus and polysplenia syndrome. Transplantation of the liver 67: 835-847.

2. Pomposelli JJ, DaCosta MA, McPartland K, Jenkins RL (2007) Retroversus implantation of a liver graft: a novel approach to the deceased donor with situs inversus totalis. Am J Transplant 7: 1869-1871.

3. Asfar S, Ozcay N, Grant D, Wall W (1995) Transplantation of the liver from a donor with complete situs inversus and dextrocardia. Transplantation 59: 442-444.

4. Herrera LA, Castillo J, Martino E, Rabanal JM, Fleitas MG, et al. (1996) Orthotopic liver transplantation from a donor with abdominal situs inversus. Transplantation 62: 133-135. 
Citation: Coelho GR, Filho JFRS, Filho ACS, Pinto LEV, Texeira CCG, Garcia JHP (2016) Liver Transplantation From Donor With Situs Inversus Totalis: Is It a Safety Procedure?. J Transplant Technol Res 6: 161. doi:10.4172/2161-0991.1000161

Page 3 of 3

5. Braun F, Rodeck B, Lorf T, Canelo R, Wietzke P, et al. (1998) Situs inversus of donor or recipient in liver transplantation. Transpl Int. 11: 212-215.

6. Dou J, Yang T, Cao JL, Gao QJ, Su YL, et al. (2010) Classical orthotopic liver transplantation from a donor with situs inversus totalis using slight rotation of the liver graft. Chin Med J 123: 1353-1355.

7. Sun XY, Qin K, Dong JH, Li HB, Lan LG, et al. (2013) Liver transplantation using a graft from a donor with situs inversus totalis: a case report and review of the literature. Case Rep Transplant.
8. Yu S, Guo H, Zhang W, Yu J, Yan S, et al. (2014) Orthotopic liver transplantation in situs inversus adult from an $\mathrm{ABO}$-incompatible donor with situs inversus. BMC Gastroenterol 13: 14-46.

9. Manzia TM, Tariciotti L, Angelico R, Toti L, Anselmo A, et al. (2015) Side-to-side cavalanastomosis in a patient receiving a liver graft from a marginal donor with situs inversus totalis. Int J Surg Case Report 6: 222-225. 